\title{
Processing order in dual-tasks when the duration of motor responses varies
}

\author{
Orden de ejecución de dos tareas cuando la \\ duración de las respuestas motoras varían
}

Recibido: junio 1 de 2012 | Revisado: agosto 1 de 2012 | Aceptado: octubre 30 de 2012

SUSANA RUIZ FERNÁNDEZ *
Leibniz Knowledge Media Research Center, Germany
TANJA LEONHARD
University of Tübingen, Germany
MARTIN LACHMAIR
Leibniz Knowledge Media Research Center, Germany
BETTINA ROLKE
ROLF ULRICH
University of Tübingen, Germany

\section{A B S T R A C T}

Recent studies reported that central processing duration influences processing order of two tasks in the psychological refractory period (PRP) paradigm. This study examined whether the duration of response execution influences the processing of task order. For this purpose, a tone discrimination task was combined with a letter discrimination task. Both tasks were presented in random order using different stimulus onset asynchronies (SOAs). In one condition, participants responded to each stimulus with a single key press (easy response condition). In the other condition, the tone task required a single key press, whereas the letter task required a more time-consuming key presssequence (hard response condition). The results showed that participants tend to perform the tone task first more often when the response requirement for the letter task is hard, rather than easy. This result is consistent with the notion that participants optimize response scheduling in dual-task situations. Key words authors

Psychological Refractory Period, Processing Order, Response Duration

Key words plus

Visual Perception, Tone Discrimination, Cognitive Science

\section{RES UMEN}

Bajo el paradigma de periodo refractario psicológico (PRP), recientes estudios han hallado que la duración del procesamiento central influye en el orden en el que dos tareas son procesadas. En el presente trabajo se examinó si la duración de la respuesta también influye en el orden en el que dos tareas se ejecutan. Para este propósito, se utilizó una tarea de discriminación auditiva en combinación con una tarea de discriminación visual. En el experimento se varió el orden de presentación de las tareas de forma aleatoria así como se utilizaron diferentes intervalos entre estímulos (stimulus onset asynchrony; SOA) En una condición, los participantes respondieron a cada estímulo pulsando una tecla (condición de respuesta simple). En la otra condición, mientras que a la tarea auditiva se respondía de nuevo pulsando una tecla, la respuesta a la tarea visual requería pulsar una secuencia de teclas, aumentando la duración de la respuesta (condición de respuesta compleja). Los resultados mostraron que los participantes tienden a ejecutar más a menudo la tarea auditiva en primer lugar cuando la respuesta de la tarea visual es más compleja. Este resultado apoya la noción de que, en escenarios de doble 
tarea, los participantes pueden invertir sus respuestas si con ello optimizan su ejecución.

Palabras clave autores

Periodo refractario psicológico, orden de procesamiento, duración

de respuesta.

Palabras clave descriptores

Percepción visual, discriminación de tono, ciencia cognitiva.

\section{Introduction}

The psychological refractory period (PRP) paradigm has often been employed to study cognitive limitations involved in dual-task performance. In a typical PRP experiment, two stimuli (S1 and S2) are presented in rapid succession and each stimulus requires a separate response (R1 and R2). The typical finding is that the reaction time (RT) of Task 2 (RT2) increases when the temporal interval -the stimulus onset asynchrony (SOA)- between $\mathrm{S} 1$ and $\mathrm{S} 2$ is shortened. This increase of RT2 is commonly referred to as the PRP effect reflecting dual-task interference that arises when both tasks overlap in time. By contrast, the reaction time of Task 1 (RT1) does not usually vary with SOA.

The central bottleneck model (Pashler, 1984; Pashler \& Johnston, 1989) provides the standard framework to explain this result pattern. The model assumes that each of the two tasks requires three successive processing stages: the perception of the stimulus, the selection of the response, and the execution of motor response. Crucially, the model assumes that the response selection stage constitutes a central bottleneck process. Consequently, if Task 1 occupies the bottleneck, processing of Task 2 has to be postponed. Accordingly, RT2 increases as SOA decreases. In contrast, RT1 should remain unaffected by SOA (for a review, see Pashler, 1994). Although the central bottleneck model provides a parsimonious account of several RT phenomena associated with the PRP paradigm, other research has indicated that processes prior to response selection (Johnston \& McCann, 2006; Koch \& Jolicoeur, 2007; Koch \& Prinz, 2002) and motor processes (Bratzke et. al., 2008; Bratzke, Rolke, \& Ulrich, 2009;; De Jong, 1993; Ruiz Fernández \& Ulrich, 2010; Ulrich, 2006) can be subject to dual-task interference as well.
The standard formulation of the central bottleneck model implies that the central processor is dedicated sequentially to each task and assumes that the central stage of Task 1 is processed first (Pashler \& Johnston, 1989). However, it leaves open whether central processing order is specified by a higher-order control mechanism, or whether this order is simply determined by a first-come, first-served principle (i.e., the stimulus that arrived first at the bottleneck also enters to the bottleneck first). Studies addressing order control in PRP-tasks tend to support the notion of a higher-order control mechanism (e.g., De Jong, 1995; Leonhard, Ruiz Fernández, Ulrich, \& Miller, 2011; Leonhard \& Ulrich, 2011; Luria \& Meiran, 2003; Ruiz Fernández, Leonhard, Rolke, \& Ulrich, 2011; Sigman \& Dehaene, 2006; Szameitat, Lepsien, Cramon, Sterr, \& Schubert, 2006; Umiltà, Nicoletti, Simion, \& Tagliabue, 1992).

Recent research has indicated that the duration of central processes can influence the processing order of Task 1 and 2 (Leonhard et al., 2011; Ruiz Fernández et al., 2011). For example, Leonhard et al. (2011) combined a more time-consuming first task with a less time-consuming second task in a PRP paradigm. Specifically, Task 1 was a mental rotation task designed to have a more timeconsuming central stage than Task 2 (Cooper \& Shepard, 1973; Shepard \& Metzler, 1971). In Task 1, participants judged whether a rotated letter was presented in its normal or in its mirror-imaged form. In the less time-consuming Task 2, participants were asked to judge whether a tone was presented to their left or to their right ear. It is noteworthy that participants were not constrained to produce the two responses in a particular order. Leonhard et al. expected that these different task demands affect the central processing order, because processing Task 2 before Task 1 should reduce Task 2 waiting time at the bottleneck (Miller, Ulrich, \& Rolke, 2009). In fact, the results of Leonhard et al. are consistent with the optimization account of Miller et al. (2009) that assumes that participants tend to perform the easier task before the harder one in order to minimize total reaction time (TRT $=\mathrm{RT} 1+\mathrm{RT} 2)$. 
While Leonhard et al. (2011) employed a traditional PRP paradigm, with one task always presented before another task, Ruiz Fernández et al. (2011) showed an influence of central processing duration on central processing order in a PRP paradigm, when task order was varied unpredictably from trial to trial. In one half of the experiment, participants performed a time-consuming mental rotation task (see Leonhard et al.) combined with a tone discrimination task, in which participants judged if a tone was presented to their left or to their right ear (hard condition). In the other half of the experiment, the mental rotation task was replaced by a less timeconsuming letter discrimination task, in which participants judged whether the letter $\mathrm{X}$ or $\mathrm{Y}$ had been presented (easy condition). In this latter condition, the central processing duration of the tone task was comparable to the one of the letter task.

Ruiz Fernández et al. (2011) assessed the response order of the two tasks as a function of SOA (Sigman \& Dehaene, 2006). For each SOA level, they computed the proportion of trials where the response to the tone task occurred before the response to the letter task. This proportion increased as a sigmoidal function from 0 (at large negative SOAs in letter-tone trials) to 1 (at large positive SOAs in tone-letter trials). From this function, they estimated the SOA level at which the proportion of tone responses attained 50\%, that is, the SOA level at which the two response orders (tone response first and letter response first), were equally likely. The authors expected that this 50\% SOA level is affected by condition (i.e., hard vs. easy) because of the different central processing times required for the letter task and for the mental rotation task. Consistent with this expectation, they observed a $255 \mathrm{~ms}$ shift in the predicted direction. Specifically, in the hard condition, participants tended to perform the less time-consuming tone task first more often than in the easy condition, especially at short SOAs, suggesting that the duration of central processes influences central processing order.

Another recent study by Huestegge and Koch (2010) also revealed that the duration of central processes influence processing order. In their dual task study, participants had to execute a saccade and a manual task to one single stimulus (i.e., tone presented to the left or the right ear). The authors manipulated stimulus-response (S-R) compatibility to vary the temporal task overlap. Specifically, in one condition the S-R mapping was spatially compatible in the saccade task, but was incompatible in the manual task, whereas in the other condition the mapping was incompatible in the manual task, but was compatible in the saccade task. In the condition with compatible saccades, but incompatible manual responses, the central overlap of the tasks was assumed to be small, because response latencies are typically shorter for saccadic than for manual responses.

In contrast, in the condition with incompatible saccades but compatible manual responses, the central overlap was presumably larger. Results showed that in the dual-task trials with the compatible saccade task, the saccades were performed first in most of the trials (98.9\%), whereas in trials with incompatible saccades, saccades were performed first less frequently ( $90.9 \%$ of the trials). Thus, the study can be interpreted as supporting the assumption that processing order is influenced by the duration of central processes.

As mentioned above, research has indicated that under certain task conditions, motor processes in dual tasking are subject to interference (Bratzke et al., 2009; Bratzke et al. ${ }^{1}$, 2008; De Jong, 1993; Ruiz Fernández \& Ulrich, 2010; Ulrich et al., 2006). Ulrich et al., (2006), for example, manipulated the duration of the first response (R1) and required their participants to respond to a tone (low vs. high) with a ballistic movement (left hand) of different distances (short vs. long). In Task 2 participants responded to a letter ( $\mathrm{X}$ vs. $\mathrm{O}$ ) with the index finger or the ring finger of the right hand. According to the central bottleneck model, R1 distance manipulation should not influence Task 2 performance. In contrast to this assumption, however, R1 distance propagated onto RT2 at short SOAs. Specifically, RT2 increased with R1 movement time

1 Bratzke et al. (2008) used similar single vs. sequential key press responses in a PRP paradigm and demonstrated both a massive effect on response duration and a motor bottleneck. 
and this propagation effect diminished, as SOA was increased. Similar results have been obtained when participants performed response sequences of different length in Task 1 (Bratzke et al., 2008; Pashler \& Christian, 1994). These results indicate that additionally to central processes, motor processes are subject to interference.

The optimization account of Miller et al. (2009) assumes that participants try to minimize the total time needed to perform both tasks. Therefore, they should perform the less time-consuming task before the more time-consuming task, in order to minimize the waiting period of the less timeconsuming task in the bottleneck, especially at short SOAs. The results of Leonhard et al. (2011) and Ruiz Fernández et al. (2011) are consistent with this notion. Both studies showed that task demands, which affect the duration of the central stage, influence the response order of the two tasks. Assuming that not only central processes, but also motor processes are subject to interference (e.g., Ulrich et al. 2006), task demands that affect the duration of the motor stage should also influence the response order of the two tasks. More specifically, if participants tend to minimize the TRT by reducing the waiting period of the less time-consuming response, they should also consider the duration of the motor stage. Accordingly, they should respond first to the task with the less time-consuming motor response and then to the task with the more timeconsuming response, especially at short SOAs.

In order to address the question whether or not the duration of motor processes would also influence processing order, the present study varies the motor demands of one task in a PRP paradigm, similarly to the study of Ruiz Fernández et al (2011). In both conditions of the present experiment, a tone discrimination task was combined with a letter discrimination task. In the easy response condition, participants responded to each task with a single key press, whereas in the hard response condition, the tone task required again a single key press, but the letter task required a time-consuming key presssequence $^{1}$. If the duration of the response affects the processing order of Task 1 and 2, we expected, on the basis of the optimization account (Miller et al., 2009), that participants would tend to finish the tone task more often before the letter task in the hard response condition (with the letter task to be hard) than in the easy response condition (with the letter task to be easy). This would minimize total performance time, because the easy task does not need to be postponed until the time-consuming hard task has been completed.

\section{Method}

Participants. 38 students ( $M=24.7$ years) of the University of Tübingen participated in this 90 min experiment. All participants reported normal hearing and normal or corrected-to-normal vision. They received either course credits or payment for their participation.

Stimuli. The stimuli of the letter discrimination task were $\mathrm{X}$ or $\mathrm{Y}$, presented in their upright position in the middle of the screen. The letters were displayed until response onset. The tone discrimination task consisted of a $523 \mathrm{~Hz}, 80 \mathrm{~dB}-\mathrm{SPL}$ tone, presented to the right or to the left ear via headphones for $100 \mathrm{~ms}$.

Apparatus. Participants were tested individually. They sat in a chair at a distance of approximately $60 \mathrm{~cm}$ from monitor, upon which the visual stimuli were presented. Auditory stimuli were presented via headphones. There was a separate response panel for each hand to register responses with the index finger and the middle finger. In the easy response condition, the letter discrimination task required a single key press with the left hand (index vs. middle finger). In the hard response condition, it required a sequence of three key presses with the left hand (index-, middle-, and index finger-sequence vs. middle-, index-, and middle finger-sequence). The assignment of the stimuli (X or $\mathrm{Y}$ ) to response fingers was balanced across participants. The tone discrimination task required a key press of the right index, or right middle finger if the tone was presented to the left or the right ear, respectively.

Procedure. Participants were instructed to respond as quickly and as accurately as possible to both tasks, emphasizing that both tasks were 
equally important. Participants were informed that these criteria were used to determine credit points for each trial and to reward the person with the highest score with $25 €$. The response order was not mentioned, unless the participant explicitly asked for it. In that case, however, the participant was told that response order was of his or her own choice.

Each trial started with the presentation of a fixation cross $\left(0.38^{\circ} \times 0.38^{\circ}\right.$ visual angle $)$ in the middle of the screen for $1,000 \mathrm{~ms}$ followed by the presentation of the first stimulus. After a variable SOA, the second stimulus was presented. After each trial, feedback was provided in the middle of the screen. If the participant responded correctly to the two tasks, the word "richtig" (correct) appeared for 1,500 ms. If one or both responses were incorrect, the word "falsch" (wrong) appeared for 2,000 ms.

Credit points were determined by means of speed and correctness of responses and were shown in black, below the feedback. To calculate the credit points, the total reaction time of the current trial i TRTi was compared ${ }_{i}$ against a weighted exponentially moving average, $\mathrm{M}$ $\left(\right.$ TRT $\left._{\mathrm{i}}\right)=0.1 \cdot\left(\mathrm{TRT}_{\mathrm{i}-1}\right)+0.9 \cdot \mathrm{M}\left(\mathrm{TRT}_{\mathrm{i}-1}\right)$. This average for the point system gives greater weight to performance in recent than previous trials and, thus, adjusts for local fluctuations in performance, such as changes due to learning or fatigue. If $\mathrm{TRT}_{\mathrm{i}}$ was smaller than $\mathrm{M}\left(\mathrm{TRT}_{\mathrm{i}}\right)$ and both responses were correct, participants obtained 50 credit points. If only one of these two criteria was achieved, participants obtained 0 points. If none of these criterions was achieved, they obtained -50 points (see Leonhard et al., 2011).

The next trial began after the disappearance of the feedback. At the end of each block, the achieved block score was indicated. A single session consisted of 14 blocks of 52 trials each. Whereas $\mathrm{SOA}$ varied randomly from trial to trial, response difficulty varied between the first and the second half of the experiment. The order of the responsedifficulty condition was counterbalanced across participants.

Design. The experiment employed a two-factor within-subjects design with factors of $\operatorname{SOA}(0, \pm 50$, $\pm 100, \pm 200, \pm 400, \pm 800$, and $\pm 1,600 \mathrm{~ms})$ and response difficulty (hard vs. easy). The dependent variables were mean $\mathrm{RT}$ of the tone task $\left(\mathrm{RT}_{\text {tone }}\right)$, mean RT of the letter task, ( $\left.\mathrm{RT}_{\text {letter }}\right)$, and accuracy for both tasks measured in percentage correct (PCtone and $\left.\mathrm{PC}_{\text {letter }}\right)$. Note that in the hard response condition, $\mathrm{RT}_{\text {letter }}$ was measured as the time needed for the first key press of the hard response. To determine the order of $\mathrm{R}_{\text {tone }}$ and $\mathrm{R}_{\text {letter }}$, the percentage of trials in which participants performed $\mathrm{R}_{\text {tone }}$ first was determined.

\section{Results}

RTs shorter than 100 or greater than 3,000 ms were considered outliers and their corresponding trials were discarded (2.4\%). Trials were only included in further analyses when both tasks were performed correctly (89\%). Accordingly, in the hard response condition the three key presses had to be performed correctly. Inter-response intervals (IRIs) are shown in Table 1. p-values were, whenever appropriate, adjusted for violations of the sphericity assumption, using the Greenhouse-Geisser correction.

We calculated for each SOA level the percentage of trials in which participants performed the tone task before the letter task. From the resulting response function, the 50\% SOA value was estimated for each condition and for each participant. This analysis was performed by the computer program PMETRIC (Miller \& Ulrich, 2003), which allows the estimation of the $50 \%$ SOA value, as well as the estimation of the steepness (DL) of the response function. Separate ANOVAs were performed for the 50\% SOA and the DL estimates.

In order to enhance comparability with other PRP-studies, RT and PC were analyzed for both presentation orders, that is, separately for letter-tone trials and for tone-letter trials. Consequently, trials in which stimuli were presented simultaneously (i.e., $\mathrm{SOA}=0$ ) were discarded. The dependent variables were submitted to analyses of variance (ANOVA) including the factors $\operatorname{SOA}(50,100,200,400,800$, and $1,600 \mathrm{~ms}$ ), as well as response difficulty (hard vs. easy). Additionally, in the hard response condition, the response duration of the letter task (i.e., 


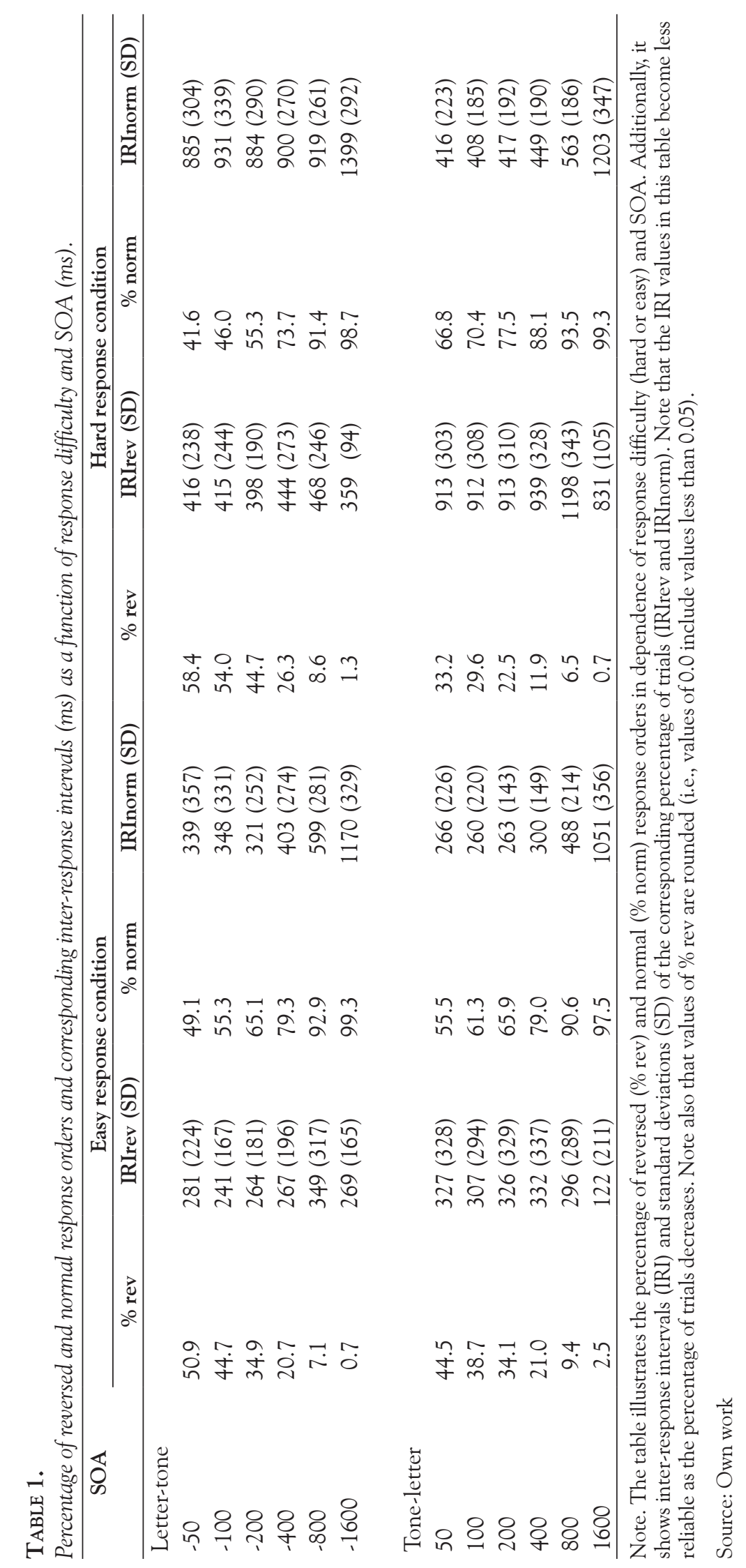


from the onset of the first key press to the offset of the third key press) was measured.

$50 \%$ SOA and DL

The location of the response function, as assessed by the $50 \%$ SOA value, was significantly affected by response difficulty, $F(1,37)=5.47, p=0.025$ (see Figure 1). In the easy condition, both response orders (i.e., first $\mathrm{R}_{\text {tone }}$ and second $\mathrm{R}_{\text {letter }}$, or first $\mathrm{R}_{\text {letter }}$ and second $\mathrm{R}_{\text {tone }}$ ) were almost equally likely performed and the response order function has a $50 \%$ SOA value of $37.3 \mathrm{~ms}$. In contrast, in the hard condition, the response sequence $\mathrm{R}_{\text {tone }}$ first and $\mathrm{R}_{\text {letter }}$ second was performed more often, producing a large negative $50 \%$ SOA value of -200.8 $\mathrm{ms}$. In other words, participants tended to perform more often the response order $\mathrm{R}_{\text {tone }}-\mathrm{R}_{\text {letter }}$ than the reverse order $\mathrm{R}_{\text {letter }}-\mathrm{R}_{\text {tone }}$ in the hard compared to the easy condition. Accordingly, the letter had to be presented $238.1 \mathrm{~ms}$ earlier in the hard than in the easy condition for attaining equal response order frequencies of $\mathrm{R}_{\text {tone }}$ and $\mathrm{R}_{\text {letter }}$.
Theoretically most important, this result shows that participants tend to perform the less time-consuming motor response before the more time-consuming one. In contrast to the 50\% SOA value, the steepness of the RT function was not significantly affected by the response difficulty, $F(1,37)=2.67, p=0.111$, indicating that this factor does not influence the overall shape of this function. Table 2 additionally illustrates the percentage of response reversals (i.e., trials where the response to the second presented task was first performed). The table shows that the percentage of response reversals is especially high in the hard response condition, if the tone follows the letter by short $\mathrm{SOAs}$ (i.e., at $\mathrm{SOA}=-50 \mathrm{~ms}$ and $\mathrm{SOA}$ $=-100 \mathrm{~ms}$ in the letter-tone trials of the hard response condition).

\section{Letter-Tone Trials}

In these trials, $\mathrm{RT}_{\text {letter }}$ and $\mathrm{PC}_{\text {letter }}$ correspond to the first-presented task and $\mathrm{RT}_{\text {tone }}$ and $\mathrm{PC}_{\text {tone }}$ correspond to the second-presented task.

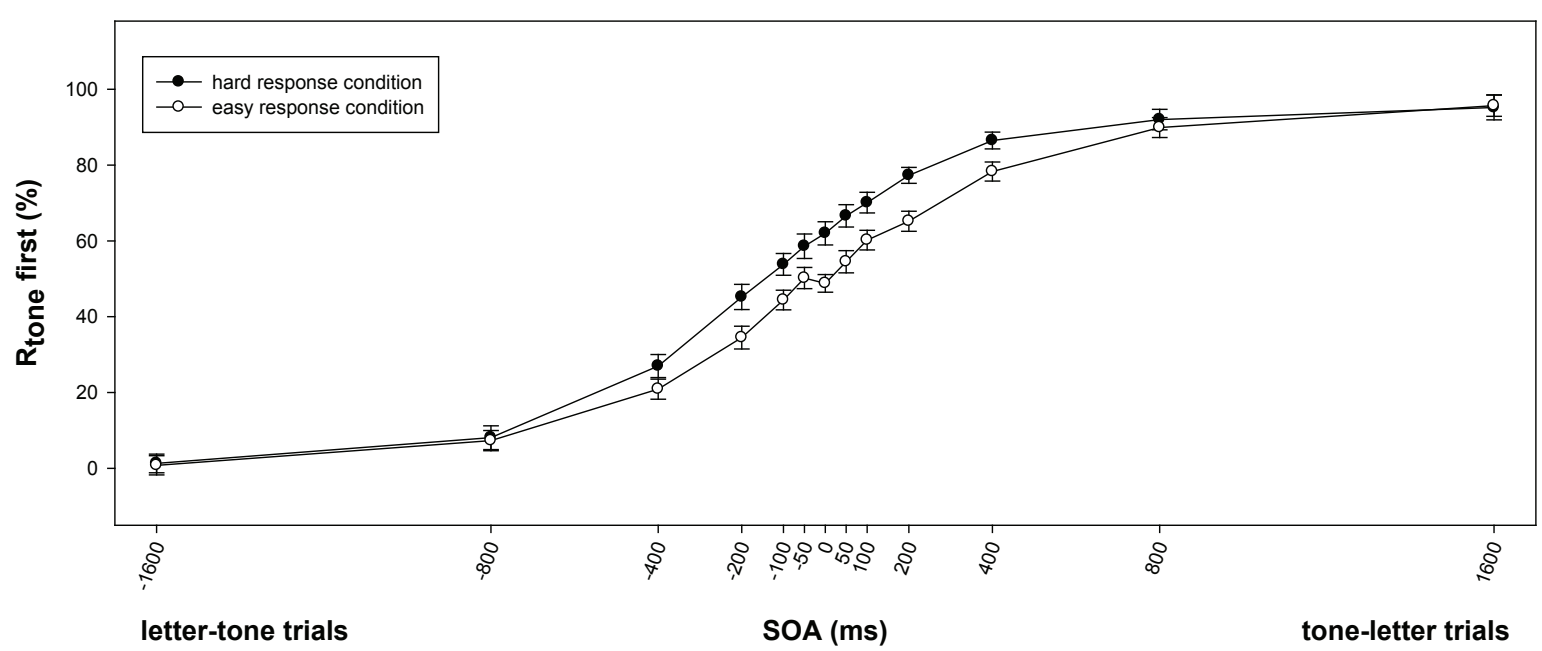

Figure 1. The response order function depicts the percentage of the tone task performed as the first task as a function of SOA between the presentation of the first stimulus (S1) and the second stimulus (S2). The functions are shown separately for the hard response condition, in which a more time-consuming response (i.e., key press sequence) for the letter task was combined with a less time-consuming response (i.e., single key press) for the tone task, and the easy response condition, in which a less time-consuming response (i.e., single key press) is required for both tasks. Note that negative SOA values correspond to the dual-task situation in which the letter was presented first. Positive SOA values correspond to the dual-task situation in which the tone was presented first. Error bars represent the within-subject standard error (Cousineau, 2005).

Source: Own work 


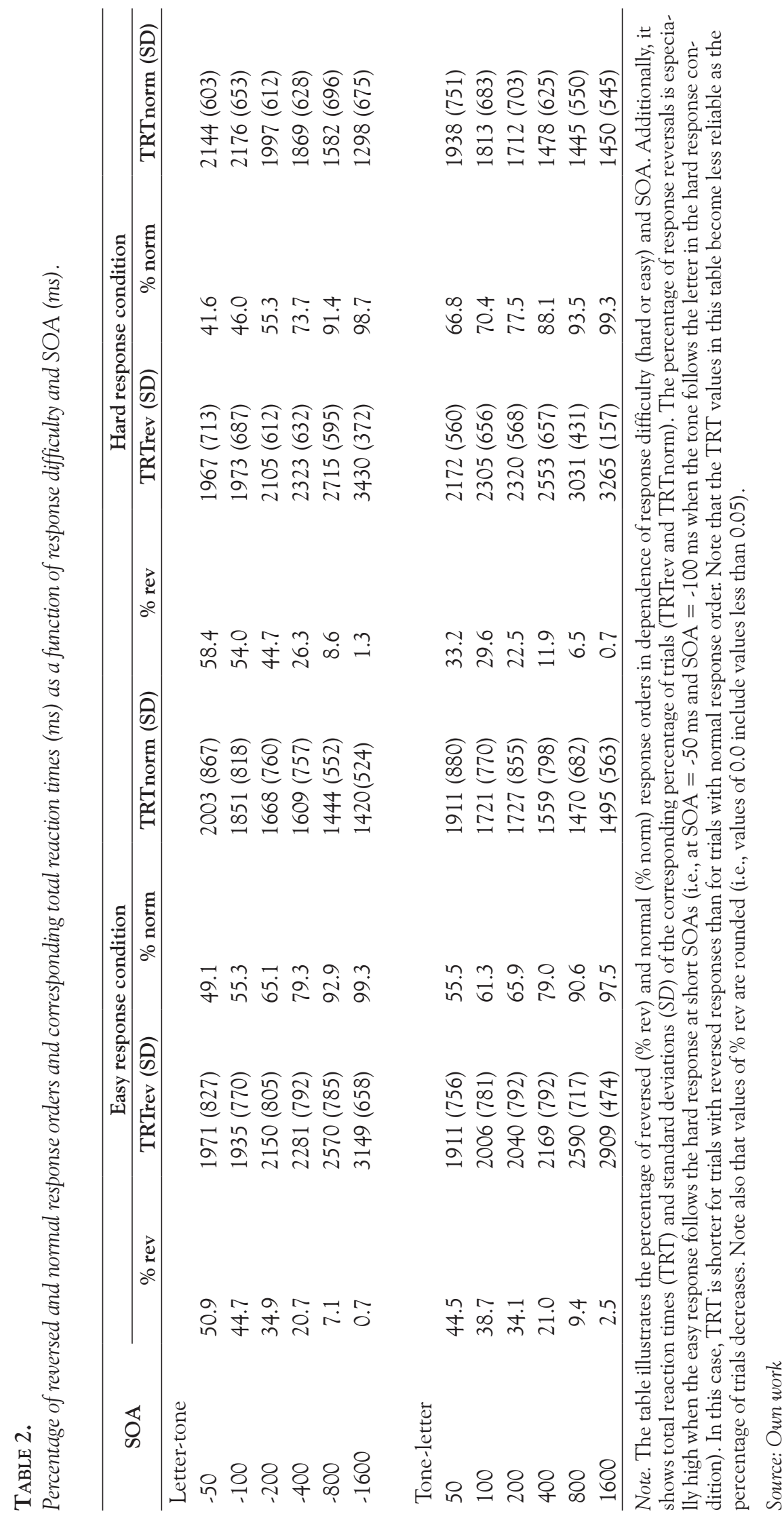


$\mathrm{PC}_{\text {letter }}$ Overall $\mathrm{PC}_{\text {letter }}$ was $98.4 \%$. ANOVA showed no significant effect on $\mathrm{PC}_{\text {letter }}$, all $p>0.1$ (see Figure 2).

$R T_{\text {letter }}$ There was a significant main effect of SOA, $F(5,185)=19.37, p<0.001$; indicating a decrease of RT with increasing SOA (see Figure 2). There was no main effect of response difficulty, $F(1,37)=2.15, p=0.151$. The factors, however, produced a reliable interaction, $F(5,185)=7.82$, $p<0.001$. Post-hoc comparisons per SOA revealed that $\mathrm{RT}_{\text {letter }}$ was significantly longer in the easy than in the hard response condition at SOAs 400, 800 and $1,600 \mathrm{~ms}($ all $p<0.05)$.

The response duration of the letter task in the hard response condition was $\mathrm{M}=544 \mathrm{~ms}$ ( $\mathrm{SD}=$ $196 \mathrm{~ms})$.

$\mathrm{PC}_{\text {tone. }}$ Overall $\mathrm{PC}_{\text {tone }}$ was $93.5 \%$. Accuracy varied over SOAs and was lowest at SOA $400 \mathrm{~ms}, F(5$, $185)=3.74, p=0.006$ (see Figure 2). Responses were $5 \%$ more accurate in the hard than in the easy condition, $F(1,37)=75.27, p<0.001$; factors did not interact, $F<1$.

$R T_{\text {tone }}$. ANOVA revealed a highly reliable PRP effect, $F(5,185)=130.38, p<0.001$ (see Figure 2). The inverted slope of the RT function at short SOAs is consistent with the notion that in some trials the tone task is performed before the letter task (cf. Leonhard et al., 2011). $\mathrm{RT}_{\text {tone }}$ was $175 \mathrm{~ms}$ longer in the hard than in the easy condition, $F(1,37)=$

$68.58, p<0.001$. This latter effect varied significantly with SOA, F $(5,185)=6.75, p<0.001$. It was smaller at extreme SOAs $(90 \mathrm{~ms}$ and $81 \mathrm{~ms}$ at $\mathrm{SOA}=50 \mathrm{~ms}$ and $1,600 \mathrm{~ms}$, respectively) and bigger at medium SOAs, with a maximum difference at $\mathrm{SOA}=400 \mathrm{~ms}(276 \mathrm{~ms})$.

\section{Tone-Letter Trials}

In these trials, $\mathrm{RT}_{\text {tone }}$ and $\mathrm{PC}_{\text {tone }}$ correspond to the first-presented task and $\mathrm{RT}_{\text {letter }}$ and $\mathrm{PC}_{\text {letter }}$ correspond to the second-presented task.

$\mathrm{PC}_{\text {tone }}$. Average $\mathrm{PC}_{\text {tone }}$ was $94.8 \% . \mathrm{PC}_{\text {tone }}$ differed across SOAs and was lowest at SOA $50 \mathrm{~ms}, F(5,185)$ $=4.88, p=0.007$ (see Figure 3). Responses were $2.1 \%$ more accurate in the hard than in the easy response condition, $F(1,37)=5.82, p=0.021$. The factors produced a marginally significant interaction, $F(5,185)=2.43, p=0.079$. At SOA $50 \mathrm{~ms}$, responses were $5.0 \%$ more accurate in the hard than in the easy response condition and at SOA $1600 \mathrm{~ms}$, responses were $1.5 \%$ more accurate in the easy than in the hard response condition.

$R T_{\text {tone }}$. There was a main effect of SOA, $F(5,185)$ $=14.86, p<.001$; when SOA was long, $\mathrm{RT}_{\text {tone }}$ was $70 \mathrm{~ms}$ longer than when SOA was short (see Figure 3). There was a marginally significant effect of response dificulty, $F(1,37)=3.1, p=0.087$. $\mathrm{RT}_{\text {tone }}$ was marginally faster $(52 \mathrm{~ms})$ in the easy than in
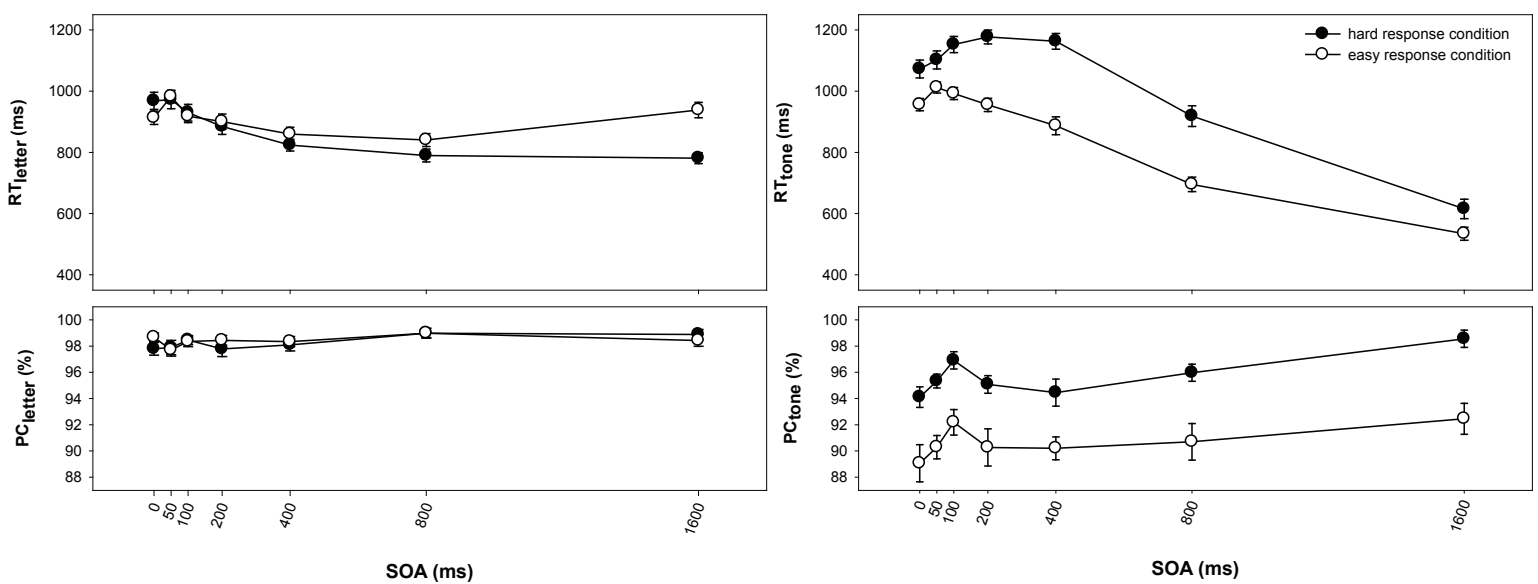

Figure 2. Reaction time and percent correct for the letter task (left side) and the tone task (right side) depending on SOA, when the letter was presented as first stimulus. The results were depicted separately for the easy and the hard response conditions. Error bars represent the within-subject standard error (Cousineau, 2005).

Source: Own work 

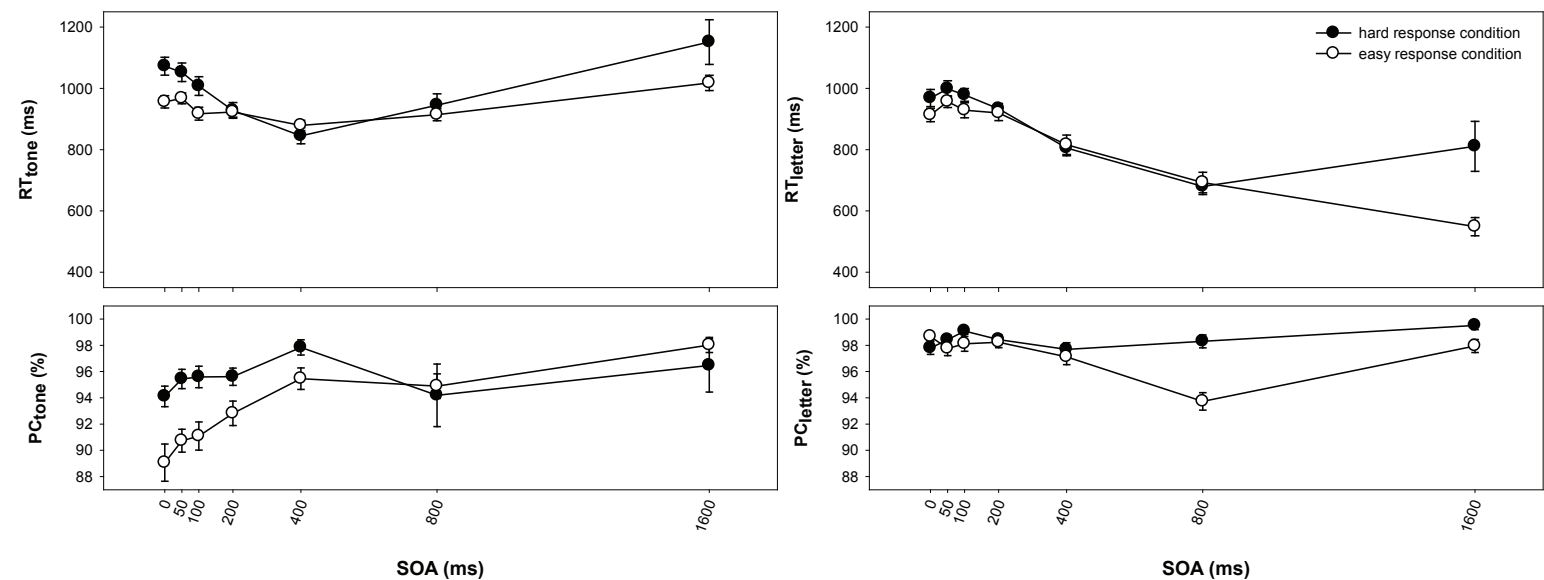

Figure 3. Reaction time and percent correct for the tone task (left side) and the letter task (right side) depending on SOA, when the tone was presented as first stimulus. Results were depicted separately for the easy and the hard response conditions. Error bars represent the within-subject standard error (Cousineau, 2005).

Source: Own work

the hard response condition; factors did not interact, $p>0.1$.

$\mathrm{PC}_{\text {letter. }}$ Overall, $\mathrm{PC}_{\text {letter }}$ was $97.9 \% . \mathrm{PC}_{\text {letter }}$ differed across SOAs and was lowest at SOA 800 ms, $F(5,185)=9.17, p<0.001$ (see Figure 3). Responses were $1.4 \%$ more accurate in the hard than in the easy response condition, $F(1,37)=14.13$, $p$ $<0.001$. The factors produced a reliable interaction, $F(5,185)=6.18, p<0.001$. At SOA $1600 \mathrm{~ms}$, responses were $2.6 \%$ more accurate in the hard than in the easy response condition. This difference diminished at SOA $50 \mathrm{~ms}$ to $0.9 \%$.

$R T_{\text {letter }}$ ANOVA revealed a clear PRP effect, $F(5,185)=31.4, p<0.001 . \mathrm{RT}_{\text {letter }}$ tends to be 58 ms longer in the hard than in the easy response condition, $F(1,37)=3.72, p=0.062$. This latter effect varied with $S O A, F(5,185)=6.14, p=0,009$. Posthoc comparisons per SOA revealed that $\mathrm{RT}_{\text {letter }}$ was significantly higher in the hard than in the easy response condition at SOAs 100 and 1,600 ms (all p < 0.05).

The response duration of the letter task in the hard response condition was $M=529 \mathrm{~ms}(\mathrm{SD}=$ $166 \mathrm{~ms})$.

\section{Discussion}

Recently, Leonhard et al. (2011) and Ruiz Fernández et al. (2011) provided evidence that the dura- tion of the central stage influences the order of central processing in PRP-tasks. Further research also indicated that, in addition to central processes, motor processes are subject to interference (e.g., De Jong, 1993). The purpose of the present study was to examine whether response duration, like central duration, influences processing order. To address this question, the present experiment manipulated the response duration of one task. Specifically, in one condition of the experiment, a tone task required a single key press, whereas a letter task required a more time-consuming key presssequence (hard condition). In the other condition of the experiment, participants responded to each task with a single key press (easy condition). Based on the optimization account of Miller et al. (2009), we assumed that participants try to minimize the total processing time. In consequence, they should tend to perform the less time-consuming response task before the more time-consuming response task. Therefore, we expected a shift of the response function between the easy and the hard condition.

The results clearly confirm this prediction. Participants more often performed the response $\mathrm{R}_{\text {tone }}$ before $\mathrm{R}_{\text {letter }}$ in the hard than in the easy response condition, especially at short SOAs, indicating that response duration affects processing order in PRP-tasks. This finding might reflect a tendency of participants to minimize TRT (see also Leonhard 
et al., 2011; Ruiz Fernández et al., 2011). Processing the easy response first is efficient at short SOAs because it reduces the waiting period of the tonetask. Consequently, these results are in line with the optimization account of dual task processing (see Miller et al., 2009). This interpretation is additionally supported by the TRT data of the present study (see Table 2). At $\mathrm{SOA}=-50 \mathrm{~ms}$ and $\mathrm{SOA}=-100$ $\mathrm{ms}$ in the letter-tone trials of the hard response condition - where response reversals are especially frequent - TRT is shorter when responses are reversed (i.e., when the easy response is performed first) than when responses are emitted according to the presentation order (i.e., when the hard response is performed first). In contrast, at longer SOAs in this condition - where participants responded according to the presentation order in the majority of trials - responding according to the presentation order seems to be more efficient in terms of TRT.

The present finding extends the results of Leonhard et al. (2011) and Ruiz Fernández et al. (2011) to response-related processes, indicating that not only central processes, but also the nature of the response itself, can affect processing order in PRPtasks. Besides this major result on the basis of the response functions, additional analyses on RT confirmed a clear PRP effect. Thus, the second presented task - if not processed first at short SOAs - was postponed until central processing of the first task was completed. Additionally, in the letter-tone trials $\mathrm{RT}_{\text {tone }}$ was longer in the hard response condition than in the easy response condition and varied significantly with SOA (see Figure 2). These two results are consistent with the idea that the effect of response duration of the letter task propagates to the tone task and diminishes as the temporal overlap of the two tasks decreases (Bratzke et al., 2008; Ulrich et al., 2006).

By looking at Figures 2 and 3, it becomes obvious that the tone task is subject to a speed-accuracy tradeoff (SAT) effect. Specifically, a prolonged RT for the tone task came along with higher PC in this task. This pattern of results is most pronounced in the letter-tone presentation order, but it is also present in the tone-letter presentation order. One explanation could be that similar responses (i.e., responses with the same number of response elements) lead to more interference than dissimilar responses, and accordingly, to more errors. Such a response crosstalk could also prevail at longer SOAs. A second explanation could be that the propagation effect caused the SAT- effect. In consequence, the increment of $\mathrm{RT}_{\text {tone }}$ through the effect of response duration could have influenced the accuracy of the tone task, causing the increment of $\mathrm{PC}_{\text {tone }}$. This explanation would account for the more pronounced SAT-effect in the letter-tone presentation order.

Results also show that in $\mathrm{RT}_{\text {letter }}$ there is an interaction between SOA and response difficulty in both presentation orders. Surprisingly, the pattern of interaction is reversed in both presentation orders (see Figure 2 and 3). Specifically, in the letter-tone presentation order, $\mathrm{RT}_{\text {letter }}$ is higher in the easy than in the hard response condition, whereas in the tone-letter presentation order, $\mathrm{RT}_{\text {letter }}$ is higher in the hard than in the easy response condition. A tentative explanation for this specific result could be that participants slightly preferred the tone task when they had to perform two equally easy responses. Therefore, they could tend to prepare the response to the tone. When the letter is first presented, a possible preparation of the tone response may involve switching costs in order to respond to the letter, consequently increasing $\mathrm{RT}_{\text {letter }}$ in the easy response condition of the letter-tone trials. On the contrary, when the tone is presented first, the response to the tone is executed and the response to the letter could be prepared and executed without switching costs. Although this explanation might explain the data pattern, it should be noted that it is somewhat speculative.

As mentioned before, the present results are consistent with the idea that the nature of the response itself can affect processing order in PRPtasks. However, one may attribute the effects on processing order to differences in the duration of the stimuli presentation, rather than to differences in response duration. Specifically, it might be argued that participants tended to process the tone first because it was only presented for $100 \mathrm{~ms}$, whereas the letter remained on the screen until the response to the letter. One then could expect that 
the tone task arrived first at the central bottleneck, at least when SOA was short. According to the firstcome, first served extension of the bottleneck, one might then argue that response reversals at short SOAs were rather due to fluctuations in central arrival times than to an optimization process modulated by response duration.

Contrary to this view, the work of De Jong (1995), Luria and Meiran (2003) and Leonhard and Ulrich (2011) indicates that task order is not simply determined on a first-come, first-served basis. For example, Leonhard and Ulrich tested the first-come, first-served assumption. The authors temporally extended the perceptual stage of the first presented stimulus so that the second presented stimulus might arrive first at the central bottleneck. Based on the percentage of response reversals, which was not influenced by this manipulation, the authors concluded that processing order is not determined by the central arrival times. According to this result, it seems unlikely that the effect observed in the present study was due to different arrival times. More importantly, the data in the present study also do not support this notion. Specifically, if response reversals would be determined by the perceptual duration of the stimuli, one might have expected that reversals would have taken place both in the easy and in the hard response condition (as presentation duration of the letter and the tone did not vary between conditions). Contrary to this idea, participants responded first to the tone more often in the hard than in the easy response condition (see Table 2).

Recently, Corallo, Sackur, Dehaene, and Sigman (2008) provided evidence that participants can reliably estimate the time needed to accomplish a task. More importantly, their results also showed that the introspective estimates of RT2 were not influenced by SOA, indicating an absence of the PRP-related processing delay in RT2. Accordingly, one could argue that the effect observed in the present study cannot reflect a tendency of participants to minimize the TRT by reducing the waiting period of Task 2. Although we cannot completely discard this possibility, it seems not plausible for us, as participants performed more response reversals in the hard response condition when both tasks considerably overlap in time (i.e., when the waiting period of Task 2 is long) than when the tasks did not overlap that much (i.e., when the waiting period of Task 2 is short). Moreover, the additional request for introspective estimates in Corallo et al's study. could have influenced the PRP situation, thus being difficult to transfer the findings of Corallo et al. to the ones of the present study.

The present results are consistent with the idea that participants perform the easier task before the harder one when both tasks considerably overlap in time (see also Huestegge \& Koch, 2010). One may be inclined, however, to attribute this effect to motor processes rather than to a strategic, top-down scheduling of response order. For example, assume that the motor programming time associated with the hard task is longer than the one related to the easy task. If motor processing of both tasks proceeds in parallel, the response associated with the easier task should occur before the response of the harder task. There are, however, several arguments against this motor time-related account.

First, there is strong evidence that motor processing cannot be performed in parallel when both tasks involve homologous limbs (Bratzke et al., 2008; Bratzke et al., 2009; De Jong, 1993; Ruiz Fernández \& Ulrich, 2010; Ulrich et al., 2006). This assumption is supported by the present study.

As can be seen in Figure 2, the effect of response duration in the first letter task propagates to $\mathrm{RT}_{\text {tone }}$ in the second task, indicating a response execution bottleneck. However, whether this response execution bottleneck may represent a genuine motor bottleneck or a monitoring process (e.g., Jentzsch, Leuthold, \& Ulrich, 2007; Welford, 1952) is beyond the scope of the present study.

Second, it is unlikely that the motor programming time of the harder task (sequential finger presses) is about $238 \mathrm{~ms}$ longer than the one of the easy task (single finger press). In the present study, a rough estimate of the influence of motor processing time can be inferred from the IRIs presented in Table 1 . The table shows that in the tone-letter presentation order, the IRIs of the non reversed 
response trials (i.e., IRInorm) in the hard response condition were $138 \mathrm{~ms}$ (in mean) longer, that in the easy response condition. Assuming that this difference is completely due to the effect of motor programming time (note that previous research documented that the effect of sequential finger presses vs. single finger press on RT is in the range 5-25 ms, e.g., Hackley \& Miller, 1995; Schröter \& Leuthold, 2009; Smulders, Kok, Kenemans, \& Bashore, 1995), it still cannot account for the whole shift of $238 \mathrm{~ms}$. Therefore, it seems more likely to us that this shift is the sign of an order control mechanism (e.g., Sigman \& Deheane, 2006) that determines the access to a structural bottleneck, for example, in order to optimize dual-task processing (Miller et al., 2009).

Thus, the present study extends the finding of Leonhard et al. (2011) and Ruiz Fernández et al. (2011) showing that processing order is not only influenced by the duration of central processes, but also by response duration.

\section{Acknowledgements}

We thank Julian Ridiger and Thilo Rommel for their assistance in data collection, as well as Daniel Bratzke and Juan José Rahona for their helpful comments. We would also thank two anonymous reviewers for constructive comments on a previous version of the manuscript. This work was supported by the DFG UL 116/11-1.

\section{References}

Bratzke, D., Rolke, B., \& Ulrich, R. (2009). The source of execution-related task-interference: Motor bottleneck or response monitoring? Journal of Experimental Psychology: Human Perception $\mathbb{E}$ Performance, 35, 1413-1426.

Bratzke, D., Ulrich, R., Rolke, B., Schröter, H., Jentzsch, I., \& Leuthold, H. (2008). Motor limitation in dualtask processing with different effectors. Quarterly Journal of Experimental Psychology, 61, 1385-1399.

Cooper, L. A., \& Shepard, R. N. (1973). The time required to prepare for a rotated stimulus. Memory and Cognition, 1, 246-250.
Corallo, G., Sackur, J., Dehaene, S., \& Sigman, M. (2008). Limits on introspection. Distorted subjective time during the dual-task bottleneck. Psychological Science, 19, 1110-1117.

Cousineau, D. (2005). Confidence intervals in withinsubject designs: A simpler solution to Loftus and Masson's method. Tutorials in Quantitative Methods for Psychology, 1, 42-45.

De Jong, R. (1993). Multiple bottlenecks in overlapping task performance. Journal of Experimental Psychology: Human Perception and Performance, 19, 965-980.

De Jong, R. (1995). The role of preparation in overlapping-task performance. The Quarterly Journal of Experimental Psychology A: Human Experimental Psychology, 48, 2-25.

Hackley, S. A., \& Miller, J. (1995). Response complexity and precue interval effects on the lateralized readiness potential. Psychophysiology, 32, 230-241.

Huestegge, L., \& Koch, I. (2010). Crossmodal action selection: Evidence from dual-task compatibility. Memory Eु Cognition, 38, 493-501.

Jentzsch I., Leuthold H., \& Ulrich R. (2007). Decomposing sources of response slowing in the PRP paradigm. Journal of Experimental Psychology: Human Perception and Performance, 33, 610-626.

Johnston, J. C., \& McCann, R. S. (2006). On the locus of dual-task interference: Is there a bottleneck at the stimulus classification stage? Quarterly Journal of Experimental Psychology: Human Experimental Psychology, 59, 694-719.

Koch, I., \& Jolicoeur, P. (2007). Orthogonal cross-task compatibility: Abstract spatial coding in dual tasks. Psychonomic Bulletin E⿱ Review, 14, 45-50.

Koch, I., \& Prinz, W. (2002). Process interference and code overlap in dual-task performance. Journal of Experimental Psychology: Human Perception and Performance, 28, 192-201.

Leonhard, T., Ruiz Fernández, S., Ulrich, R., \& Miller, J. (2011). Dual-task processing when Task 1 is hard and Task 2 is easy: Reversed central processing order? Journal of Experimental Psychology: Human Perception and Performance, 37, 155-136.

Leonhard, T., \& Ulrich, R. (2011). Determinants of central processing order in PRP paradigms: Central arrival times, detection times or preparation? 
The Quarterly Journal of Experimental Psychology, 64, 2012-2043.

Luria, R., \& Meiran, N. (2003). Online order control in the psychological refractory period paradigm. Journal of Experimental Psychology: Human Perception and Performance, 29, 556-574.

Miller, J., \& Ulrich, R. (2003). A computer program for the Spearman-Kärber and Probit analysis of psychometric function data. Behavior Research Methods, Instruments, $\mathcal{E}$ Computers, 36, 11-16.

Miller, J., Ulrich, R., \& Rolke, B. (2009). On the optimality of serial and parallel processing in the psychological refractory period paradigm: Effects of the distribution of stimulus onset asynchronies. Cognitive Psychology, 58, 273-310.

Pashler, H. (1984). Processing stages in overlapping tasks: Evidence for a central bottleneck. Journal of Experimental Psychology: Human Perception and Performance, 10, 358-377.

Pashler, H. (1994). Dual-task interference in simple tasks: Data and theory. Psychological Bulletin, 116, 220-244.

Pashler, H., \& Christian, C. (1994). Bottlenecks in planning and producing vocal, manual, and foot responses (Center for Human Information Processing Technical Report), La Jolla, CA: University of California, San Diego, Center for Human Information Processing.

Pashler, H., \& Johnston, J. C. (1989). Chronometric evidence for central postponement in temporally overlapping tasks. The Quarterly Journal of Experimental Psychology A: Human Experimental Psychology, 41, 19-45.

Ruiz Fernández, S., Leonhard, T., Rolke, B., \& Ulrich, R. (2011). Processing two tasks with varying task order: Central stage duration influences central processing order. Acta Psychologica, 137, 10-17.
Ruiz Fernández, S., \& Ulrich, R. (2010). Late Backward Effects in the Refractory Period Paradigm: Effects of Task 2 Execution on Task 1 Performance. Psychological Research, 74, 378-387.

Schröter, H., \& Leuthold, H. (2009). Motor programming of rapid finger sequences: Inferences from movement-related brain potentials. Psychophysiology, 46, 388-401.

Shepard, R.N., \& Metzler, J. (1971). Mental rotation of three-dimensional objects. Science, 171, 701-703.

Sigman, M., \& Dehaene, S. (2006). Dynamics of the central bottleneck: Dual-task and task uncertainty. PLoS Biology, 4, 1227-1238.

Smulders, F.T.Y., Kok, A., Kenemans, J.L., \& Bashore, T.R. (1995). The temporal selectivity of additive factor effects on the reaction process revealed in ERP component latencies. Acta Psychologica, 90, 97-109.

Szameitat, A.J., Lepsien, J., Cramon, D. Y., Sterr, A., \& Schubert, T. (2006). Task-order coordination in dual-task performance and the lateral prefrontal cortex: An event-related fmri study. Psychological Research, 70, 541-552.

Ulrich, R., Ruiz Fernández, S., Jentzsch, I., Rolke, B., Schröter, H., \& Leuthold, H. (2006). Motor limitation in dual-task processing under ballistic movement conditions. Psychological Science, 17, 788-793.

Umiltà, C., Nicoletti, R., Simion, F., \& Tagliabue, M.E. (1992). The cost of a strategy. European Journal of Cognitive Psychology, 4, 21-40.

Welford, A.T. (1952). The "psychological refractory period" and the timing of high-speed performancea review and a theory. British Journal of Psychology, 43, 2-19. 